Artigo

\title{
TEATRO HILLBROW: PERSPECTIVAS HISTÓRICAS E POLÍTICAS DE UM TEATRO ATUANDO NA LOCALIDADE AFRO-MIGRANTE DE JOHANNESBURGO - ÁFRICA DO SUL
}

HILLBROW THEATER: HISTORICAL AND POLITICAL PERSPECTIVES OF A THEATER ESTABLISHED IN THE AFRO-MIGRANT LOCALITY OF JOHANNESBURG - SOUTH AFRICA

TEATRO HILLBROW: PERSPECTIVAS HISTÓRICAS Y POLÍTICAS DE UN TEATRO ACTUANDO EN EL BARRIO AFRICANO-MIGRANTE DE JOHANNESBURGO, SUDÁFRICA

\section{Adriana Miranda da Cunha}

Adriana Miranda da Cunha Doutoranda em Teatro pelo Programa de Pós-Graduação em Teatro na Universidade do Estado de Santa Catarina (UDESC). Atua como pesquisadora em questões ligadas à performance, políticas do corpo, corporeidade e subjetividade. 


\section{Resumo}

Este texto tece diretrizes de um estudo de caso sobre as práticas teatrais de um teatro inserido no contexto pós-apartheid da África do Sul, de contorno político-social. Este teatro é feito pelo grupo estabelecido no Teatro Hillbrow, na cidade de Johannesburgo. No contexto em que o grupo se insere, configuram-se cosmologias existenciais de saberes múltiplos devido ao legado de separatismo étnico e à intensa mobilidade histórica de africanos no local. Os moradores do bairro, em sua maioria constituída de imigrantes, buscam sentidos de cidadania possíveis entre arranjos e acordos sociais baseados na precariedade e na transitoriedade. Este teatro abriga hoje a Outreach Foundation, uma organização não governamental (ONG) que desenvolve programas de desenvolvimento teatral que se relacionam com complexidades sociais tamanhas, que operam como uma plataforma de fruição em arte, educação e transformação para os jovens participantes.

Palavras-chave: Teatro em contexto, Teatro Hillbrow, Migração, Arte política.

\section{Abstract}

The text provides guidelines for a case-study of political and social aspects on theatrical practices of a theater set in the post-apartheid context of South Africa. This theater is made by the group established at the Hillbrow Theater in the city of Johannesburg. In the context of this group, existential cosmologies of multiple knowledges are formed due to the legacy of ethnic separatism and the intense historical mobility of Africans in the area. Residents of the neighbourhood, mostly migrants, seek meaningful citizenship between social arrangements and agreements based on precariousness and transience. This theater houses today the Outreach Foundation, a non-governmental organization (NGO) that develops theatrical development programs immersed in a context of such enormous social complexities that they operate as a platform for art, education and transformation for the young participants.

Keywords: Theater in context, Hillbrow Theater, Migration, Political art. 


\section{Resumen}

El texto teje directrices de un estudio de caso de contornos sociales y políticos en las prácticas teatrales de un teatro que se inserta en el contexto del posapartheid de Sudáfrica. Este teatro es realizado por el grupo establecido en el Teatro Hillbrow, en Johannesburgo. En el contexto de este grupo hay cosmologías existenciales del conocimiento múltiple debido a la herencia de separación étnica y a la movilidad histórica intensa de los africanos en este lugar. Los residentes del vecindario, en su mayoría inmigrantes, se encuentran en busca de posibles direcciones de ciudadanía entre los acuerdos sociales y acuerdos basados en la precariedad y transitoriedad. Este teatro actualmente alberga al Outreach Foundation, una organización no gubernamental que desarrolla los programas de desarrollo teatrales inmersos en un contexto de grandes complejidades sociales, operando como una plataforma de disfrute en el arte, educación y transformación de los jóvenes participantes.

Palabras clave: Teatro en contexto. Teatro de Hillbrow. Migración. Arte político.

\section{A questão da memória em Hillbrow, o bairro'}

Hillbrow, um bairro localizado na região central da cidade de Johannesburgo, África do Sul, é hoje considerado uma das principais áreas de diversidade humana no mundo por conta do grande número de ocupações, legais e ilegais, de imigrantes vindos principalmente de todo o continente africano. Lugar de resiliência, reinvenção e caos, o bairro vem sofrendo contínuas intervenções do Estado e da iniciativa privada, que o veem como um local complexo e de oportunidades para a exploração imobiliária. Por ser um bairro de abandono em termos de políticas públicas, é também um bairro de interesse

1. Este é um trecho da tese de doutorado da autora, que se encontra em processo e em fase de desenvolvimento textual, com pesquisa em andamento desde de 2016, e que prevê seu término em 2020. Aqui estão algumas premissas descritivas do projeto do Teatro Hillbrow. O trabalho de campo será dividido em dois momentos: de julho a dezembro de $2017 \mathrm{e}$ outro no segundo semestre de 2018. O objetivo da pesquisa é historicizar e analisar as práticas teatrais do Teatro Hillbrow, inseridas no contexto pós-apartheid. 
para os processos contínuos de gentrificação², que visam altos lucros. Os conceitos de reinvenção e reformulação urbanas são continuamente cooptados por ações do mercado imobiliário, bem como do poder político, fazendo que as dinâmicas de higienização, com a consequente marginalização dos mais pobres, seja uma ação naturalizada em algumas áreas da vizinhança.

O bairro, repleto de arranha-céus construídos na era de ouro da construção civil e dos investimentos internacionais entre as décadas de 1960 e 1970, foi, durante longo período, morada da população branca da cidade. Porém, a partir de 1980, passou a ser vista como "área cinza" por conta da presença, principalmente, de indianos e coloridos ${ }^{3}$. Nesse período e durante a década posterior, muitos de seus prédios foram continuamente abandonados, resultado do movimento civil que antecede a queda do apartheid 4 e o período de transição ${ }^{5}$. Esse foi um tempo significativo no qual o país encontrava-se à beira de uma guerra civil. No entanto, a intensa campanha de pacificação nacional, que teve como principal porta-voz o líder Nelson Mandela, fez com que as ondas de reocupação dos bairros centrais da capital Johannesburgo, ocorridas a partir de 1990, tornassem-se conflitos contidos em determinados locais. Esses arranha-céus, alguns conhecidos hoje como Isinyama ou prédios escuros (WILHELM-SOLOMON, 2013), são permeados por muitas disputas espaciais ligadas a questões sociopolíticas e étnicas. Tais abandonos ocorreram concomitantemente, primeiro, por parte dos brancos que ali viviam

2. Gentrificação, termo forjado pelos estudos urbanistas, que prevê a revitalização de áreas decadentes de partes das cidades ou bairros, pautada no embelezamento e aumento do comércio, seguido da valorização imobiliária, que geralmente desconsidera a parte mais pobre da população, tornando-se uma forma de revitalização extremamente excludente (BREMMER, 2000).

3. Tradução de: coloured. Categoria oficial de raça, nos períodos apartheid e pós-apartheid, que designa mestiços, povos negros descendentes dos Khoi-San (negros indígenas com coloração de pele mais clara), indianos, árabes, judeus e em alguns períodos, chineses.

4. Regime legislativo estabelecido em 1948 baseado na distinção de raças que previa uma série de privilégios socioeconômicos e separava as regiões geograficamente, em áreas para brancos, coloridos e negros, prevendo passaportes de autorização para circulação dos negros em determinadas áreas restritas para brancos, e alguns privilégios para os coloridos que eram mestiços, indianos, árabes, e os herdeiros do povo Khoi-San (que possuem feições suaves e pele de cor mais clara). O regime foi responsável pelo desalojamento de milhares de famílias negras e indígenas, bem como a prisão e morte de ativistas negros e brancos que lutavam contra ele. Seu fim se deu em 1990.

5. Período mais crítico entre 1990 e 1994, quando o primeiro presidente negro se elege, Nelson Mandela, e que se estende até os dias de hoje prevendo a transferência dos poderes político e econômico das mãos dos brancos para os negros. 
em maioria até a década de 1970; depois por múltiplas ondas de ocupações por parte de sul-africanos negros de distintos grupos étnicos e, posteriormente, por imigrantes vindos de outros países africanos buscando asilo político.

O movimento migratório de africanos para a África do Sul intensifica-se devido ao panorama conflituoso que o continente africano enfrenta a partir da década de 1950 com as diversas guerras eclodidas por conta das lutas libertárias e em resposta ao imperialismo protecionista europeu. Outro fator fundamental que acirra a migração para o país é a opressão econômica mundial, que no século $\mathrm{XX}$ tem como característica marcante a extrema desigualdade, assolando muitos países africanos com a pobreza e forçando o início de um dos maiores movimentos migratórios negros da história ocidental moderna. Portanto, por meio da topografia histórica de Hillbrow é possível acessar camadas da memória territorial africana que vão além daquele bairro específico, mas relacionada às rotas humanas naquele continente, impregnadas de histórias de lutas e injustiças.

Em Hillbrow, por conta de sua memória migratória, as dinâmicas constitutivas das relações sociais são forjadas na transitoriedade: de teto, de modos, de subsistência, de infraestrutura e de senso de cidadania. No entanto, em meio a tantas formas de precariedade, surgem modos estruturantes de relação que se sustentam e se protegem, que se fazem-desfazem-refazem e que, na sua transitória duração, são como vínculos solidificados em pontes necessárias para as travessias existenciais. Nesses modos estruturantes de relação, belos e muitas vezes sujos, há a formação de guetos nos quais a sobrevivência depende de arquiteturas relacionais às quais um ser se encontra com o outro por meio de identidades múltiplas, mas também por meio do medo. $A$ localidade é, ao mesmo tempo, lugar de entrada de imigrantes, lugar de transição de alguns modos de vida para outros, e lugar de resistência ao abandono político e social daquela sociedade de Johannesburgo imersa em políticas extremas de securitização ${ }^{6}$, parte da economia de perfil fortemente neoliberal.

6. Termo amplamente explorado por Bauman (2003), Negri e Hardt (2016) que se refere ao processo de transformação política de base capitalista, com raízes profundamente neoliberalistas e tem como consequência a extrema desigualdade econômica; o aumento da criminalização; a violência; e a insegurança civil. Para proteger as elites desse processo, surge então o mercado da segurança privada. Esse seria então o processo de securitização das sociedades contemporâneas. 
Teatro Hillbrow: perspectivas históricas e políticas de um teatro atuando na localidade afro-migrante de Johannesburgo - África do Sul

A existência de alguns prédios conhecidos como "prédios maus" (bad buildings) ou "prédios escuros" (dark buildings) revela aspectos da contradição social relacionada à desigualdade e ao abandono. Eles são locais para não estar - são desprovidos de condições mínimas de sobrevivência, já que não possuem luz, água ou coleta de lixo. No entanto, eles acomodam centenas de famílias, inclusive crianças e jovens, que migram de muitos países da África buscando melhores condições de vida. Ao chegar a Johannesburgo esses imigrantes enfrentam dinâmicas de dificuldade extrema, se veem desprovidos de seus bens, documentos, familiares, conexões, cultura e encontram níveis por vezes exacerbados de xenofobia, burocracias indevidas, corrupção por parte das instituições governamentais, duras leis para asilo político, perseguição policial, deportação, extorsão, submissão, extrema pobreza, desemprego, falta de moradia, fome, insalubridade, estigmatização e marginalização (WILHELM-SOLOMON, 2013; LANDAU, 2014).

Figura 1 - Um dos prédios ocupados, conhecidos como prédios escuros (dark buildings), este localizado na divisa não gentrificada entre Hillbrow e Centre Building District (CBD). Foto de minha autoria, tirada durante a passeata dos estudantes contra os ataques xenofóbicos ocorridos em 2013

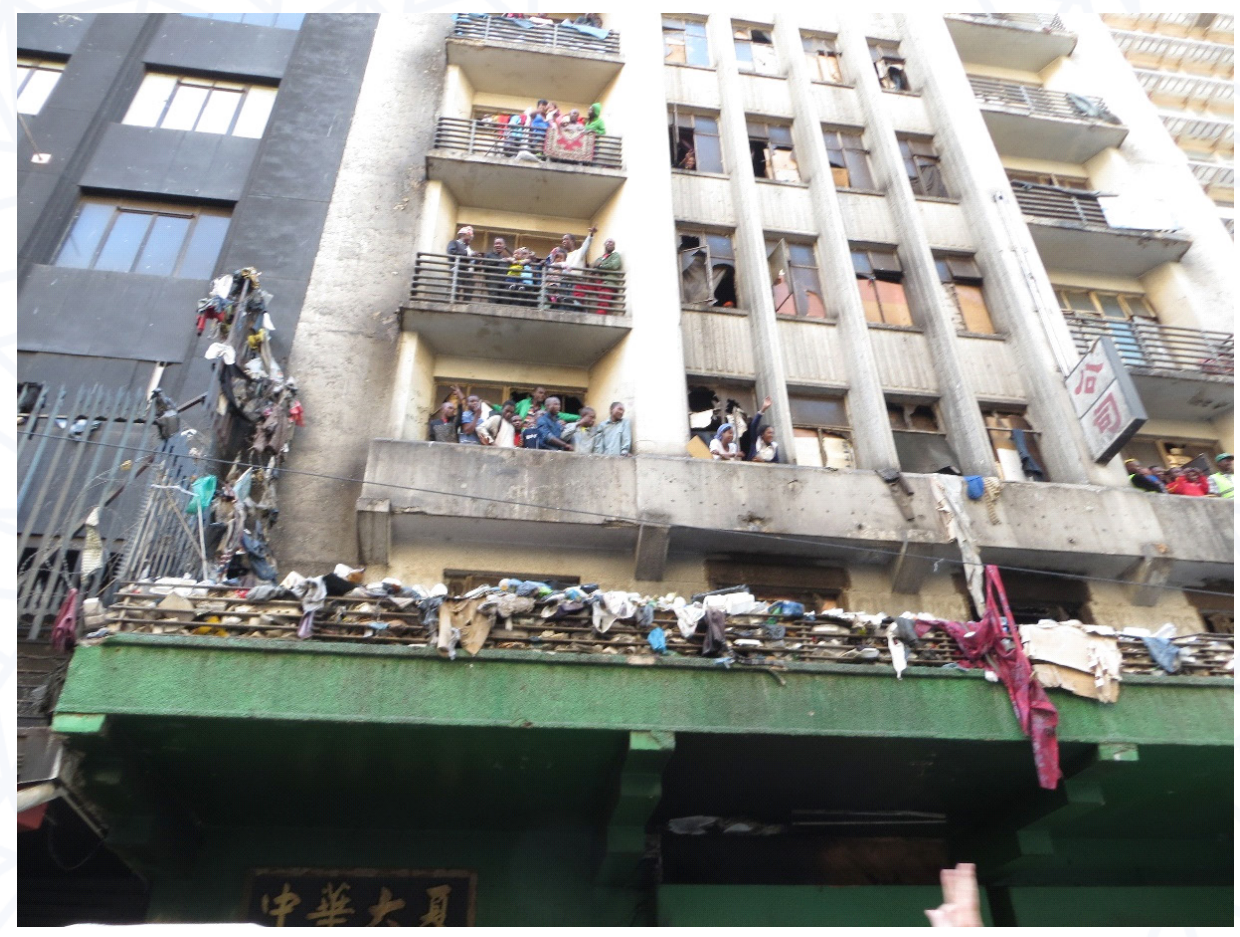

É neste contexto, de ontologias diversas e de memórias justapostas, que se encontra o Teatro Hillbrow. Ele se sustenta por meio de práticas diversas de subsistência, ativismo e arte. O espaço teatral, que é hoje conhecido por 
Teatro Hillbrow, tem uma grande relevância para crianças e jovens moradores da localidade, pois tornou-se um espaço de estar, e de criação de sentido de muitas das dinâmicas vividas por eles. Sem muitas opções de espaços urbanos públicos ou comunitários, como praças e parques, o teatro é um dos poucos locais seguros em que jovens e crianças, sul-africanas e imigrantes, podem ter acesso, antes ou depois do horário escolar.

No espaço configuram-se sete frentes de trabalhos comunitários: o Projeto Teatro Hillbrow, o Projeto Jovem Dia-Visionário, o Centro de Música, o Centro de Aconselhamento, o Centro de Artesanato, o Centro de Computação, e a Colônia de Férias ${ }^{7}$. Por conta da abrangência das frentes de atuação junto com comunidade, o espaço do Teatro Hillbrow cumpre múltiplos papéis naquela comunidade. Ali opera a Outreach Foundation, uma organização não governamental (ONG) inaugurada em 2009, que coordena tais frentes de atuação com coordenadores específicos em cada área. No projeto teatral, o coordenador Gerard Bester, nascido e criado no bairro, conhece, visceralmente, as narrativas das ruas que compõem o bairro, bem como as memórias da edificação daquele espaço teatral. Bester era uma criança do bairro quando o teatro foi erguido.

O foco desse relato encontra-se no Projeto Teatro Hillbrow. Busco descrever alguns aspectos relevantes das práticas teatrais desenvolvidas no espaço, bem como da fricção entre arte e política contidas em tais práticas. Mais especificamente, estou interessada nas memórias das pessoas que ali coexistem ou trabalham e que refletem a topografia histórica do bairro. As memórias tecem uma colcha de retalhos que representam a realidade transitória do bairro, numa retroalimentação temática entre vida e arte, como veremos mais à frente no texto.

No projeto existem dois programas distintos de engajamento com a localidade. O primeiro é o After School Programme, no qual moradores da vizinhança (neighbourhood) se deslocam até o espaço teatral, e dois facilitadores atuam juntamente com os participantes: Gcebile Dlamini, que trabalha com os alunos secundaristas e adolescentes, e Sibusiso Nkwethu Hadebe, que atua com os alunos primários e as crianças. O segundo é o High School Programme, no qual

7. No original:The Hillbrow Theatre Project, Day-vision Youth Project, Music Centre, Counselling, Boitumelo Craft Centre, Computer Centre, Kid's week. 
facilitadores vão às escolas secundárias ao redor do bairro, e no bairro Soweto8. Este segundo programa encontra-se sob o gerenciamento de Linda Michael Liwewe Mkhwanazi (Mike) e Malvin Phana Dube (Phana), que coordenam cerca de 31 facilitadores que operam nas escolas. O programa resulta no festival anual High School Drama Festival, que reúne os participantes vindos das escolas.

Para melhor compreender as dinâmicas das práticas teatrais que ali ocorrem, dinâmicas estas atravessadas pelo contexto no qual estão inseridas - sendo o contexto a razão de sua existência, a própria potência de sua força de ação e criação - alinho-me com uma estrutura teórica capaz de iluminar nossa compreensão. Vejo no termo "teatro em contexto" esculpido por Hugo Cruz, por ora, uma possibilidade justa de nomeação ao tipo de teatro que o grupo desenvolve. Essa premissa foi pensada diante das conversas mantidas com os fazedores de teatro do projeto Hillbrow e da percepção de que muitas das temáticas trabalhadas, tanto em sala de aula quanto em espetáculos, nascem das próprias experiências vividas pelos moradores no bairro.

Penso que as zonas de liminaridade ${ }^{9}$ - aquelas orlas sociais transitórias nas quais as hierarquias são temporariamente suspensas durante os ritos se manifestam naquelas práticas representadas tanto no teatro como na vida dos participantes. $O$ conceito de liminaridade fala sobre a dialética relação entre as estruturas e antiestruturas sociais que se tornam permeáveis durante os rituais, no caso, teatrais. A liminaridade seria um espaço/tempo transitório "entre" o antes e o depois, no qual o sujeito vivencia uma condição social efêmera fora de sua estrutura social. Para Turner (1995), é nesse espaço que se originam as communitas ${ }^{10}$, em sendo seus pressupostos o surgimento espon-

8. Soweto, abreviação de South Western Town, é o bairro negro criado quando houve o estabelecimento do apartheid, para onde foram deslocados todos os negros que viviam nas regiões que foram decretadas como "apenas brancos" (whites only). Bairro onde morava Mandela quando foi preso, e, hoje, sua casa transformou-se num museu. Foi no bairro também que houve a insurreição das crianças negras (1976) contra o ensino do idioma africâner e maus tratos em suas escolas, onde muitas foram mortas pela polícia dando início aos violentos enfrentamentos civis que resultaram no fim do regime separatista.

9. Relaciono-me aqui com que foi, primeiramente, cunhado por Victor Turner (1995) em seus estudos sobre rituais e performance Ndembu, que é amplamente explorado por lleana Diéguez Caballero no livro Cenários Liminares: teatralidades, performances e política (2011).

10. Termo esculpido por Vitor Turner a partir dos estudos sobre a liminaridade e as simbologias subjacentes nos rituais, que se refere a uma forma de antiestrutura constituída pelos vínculos entre indivíduos ou grupos sociais que compartilham uma condição liminar em momentos especificamente ritualizados (NOLETO; ALVES, 2015). 
tâneo, a autogestão, a autonomia e a não hierarquia. Nesse sentido, o projeto teatral, naquele contexto social, cumpre um papel importante enquanto arte política para aqueles jovens e crianças na construção de ideias de cidadania.

Peter Pál Pelbart (2008), quando escrutiniza teorias sobre o comum em sua cartografia da grupalidade, constrói uma topografia de conceitos atuais acerca dos arranjos sociais que criam paradigmas de comunidade. Tais paradigmas não se relacionam com pensar o conceito de comunidade sob uma ótica de simplificação das relações sociais por meio de unidades identitárias, ao contrário, pensar arranjos comunitários na contemporaneidade pressupõe a não homogeneidade, a pluralidade, a diversidade e multidimensionalidade.

Acredito que a problematização do conceito da vida em "comum-unidade"11, da vida na vizinhança e das múltiplas precariedades dos vínculos em espaços nos quais a economia do abandono (POVINELLI, 2011) impacta a constituição existencial das vidas dos seres humanos no liberalismo tardio. Há formas de resistência por parte das minorias que se configuram a partir de um "aquilo-outro"12, um barulho que se produz em todos os arranjos, que produzem simultaneamente seus desarranjos e rearranjos, para desafiar formas engessadas de poder. Identifico, no bairro, um tipo de inserção naquele contexto sociopolítico, que por si só já possui especificidades históricas e características de imbricamentos complexos que perpassam categorias de raça, gênero e classe, mas também de nacionalidade, de segurança civil, de necropolítica, de cidadania, de mobilidade humana e migração e de compreensão dos impactos das forças econômicas de constituição neoliberalistas que operam global e localmente na África.

Os interesses nesse espaço/tempo chamado Teatro Hillbrow e suas práticas teatrais vão além do registro técnico categórico ou analítico de premissas de um teatro em contexto, na comunidade/vizinhança. Eles justamente se entrelaçam com geontologias, ou seja, com justaposições possíveis entre a biopolítica e a ecologia política, questionando as estruturas de vida/não vida na relação entre poder, política e ética.

11. Aqui, brinco com as palavras...

12. Termo esculpido pela antropóloga e filósofa Elizabeth Povinelli em Geontologias do aquilo-outro (2016). 


\section{Apontamentos sobre o teatro Hillbrow: estruturas, relatos, memórias, encontros, travessias, processos e pensamentos}

O lugar da"precariedade, em diálogo com a vida"(CABALLERO, 2011 p.20).

O Teatro Hillbrow localiza-se na esquina da rua Kapteijn com a rua Edith Cavell - ambas as ruas, com nomes ligados à história de brancos europeus, revelam as contradições da própria história do passado do bairro. Edith Cavell, por exemplo, foi uma enfermeira britânica, branca, considerada heroína na Primeira Guerra Mundial. Ela servia à Cruz Vermelha e, de forma oculta, atuava como facilitadora de fugas de prisioneiros de guerra em Bruxelas. Foi delatada depois de salvar centenas de vidas e, mesmo com a indignação dos aliados e países neutros, como os Estados Unidos, por sua condenação, foi executada pelo exército alemão em outubro de 1915. Kapteijn é um sobrenome comum holandês, que demonstra a presença branca no passado de Hillbrow.

A edificação externa do teatro é simples, não parece um teatro e nem possui nenhuma arquitetura tradicional dos teatros de origem europeia. Ele foi construído na década de 1970 numa iniciativa de desenvolvimento missionário da Igreja Luterana Alemã, que edificou uma escola alemã (que existe até os dias de hoje); um asilo alemão; e o teatro, inaugurado sob o nome Andre Huguenot Theatre. De sua inauguração até o período do fim do apartheid, o espaço tinha um perfil bastante conservador e apresentava textos dramatúrgicos de autores britânicos e africâneres para a comunidade branca local.

Com a queda do apartheid, o bairro entra no período chamado de transição, que prevê a redistribuição de privilégios sociais, econômicos e institucionais, e o espaço teatral é esvaziado de sentido naquela configuração pela própria reocupação negra no bairro. A igreja luterana, então, resolve oportunizar iniciativas artísticas que pudessem criar conexões com a nova realidade do entorno e convida fazedores de teatro negros que ali atuavam a desenvolver projetos de cunho comunitário. Acontece que, durante a transição, os registros de memória do espaço foram perdidos. Não há fontes de pesquisa construídas que disponham das narrativas dos fatos ocorridos naquele tempo/espaço. 
O que há são as vagas histórias orais de conflitos e de disputas, que parecem ser dolorosas para aqueles que as viveram. Nas conversas que tive até agora para esta pesquisa, que se encontra em andamento, as três pessoas que viveram naquele período e que ali permanecem atuando, demostraram hesitação ao falar sobre ele. É como se a memória deste período fosse não visitável ou irrelevante, ou ainda como se elas estivessem há muito tempo enterradas ou esquecidas - falam como se o agora fosse desconectado do antes.

O teatro fica no primeiro andar de um prédio de arquitetura moderna, com sacadas desiguais de concreto aparente. A sala de apresentações possui a capacidade de acomodar setecentas pessoas, um palco de madeira antiga com proscênio, cortinas, coxias, bastidores, equipamento de luz e som. As cadeiras vermelhas, que devem ter sido um dia confortáveis, estão desgastadas e desbotadas pelo tempo. Os corredores e escadas ao lado da sala de apresentações levam às salas de aulas na parte de trás do teatro. $\mathrm{O}$ cheiro é de história antiga. Ali acontecem as aulas/encontros entre facilitadores e participantes. Na parte externa no pátio de trás foi inaugurado, em 2013, a ala nova do teatro, com duas salas construídas com forte estrutura de ferro, piso laminado de madeira e amplas janelas de vidro. Anexo à esta parte, foi construído um anfiteatro em estilo grego, para apresentação de dança, teatro e música.

Nessas premissas, juntamente com algumas salas no primeiro andar, funcionam as sete frentes de trabalho da Outreach Foundation, a ONG mista em raças e nacionalidades, que ainda mantém fortes vínculos com a Igreja Luterana Alemã - ainda proprietária do imóvel. De acordo com Gerard Bester, o coordenador do projeto teatral, a relação com a igreja é historicamente complexa e confusa.

O Projeto Teatro Hillbrow, ou apenas Teatro Hillbrow, tem em seu time seis facilitadores que coordenam dois programas principais: o After School Programme e o High School Programme. O After School acontece dentro das premissas do teatro, e tem como facilitadores principais Gcebile, responsável por alunos da faixa etária entre 13 e 17 anos, e Sibusiso, que atua com crianças entre 4 a 12 anos. Sibusiso conta que é bastante desafiador trabaIhar com esta faixa etária, pois os encaminhamentos se diferenciam muito entre os grupos estabelecidos de acordo com os horários de atividade. Ele 
Teatro Hillbrow: perspectivas históricas e políticas de um teatro atuando na localidade afro-migrante de Johannesburgo - África do Sul

prefere, por vezes, separar os participantes em dois grupos para poder oferecer atividades mais adequadas de acordo com as faixas etárias. Sibusiso fala também da inconstância de seus grupos, pois as crianças são muito suscetíveis às vidas dos pais e suas jornadas de trabalho. Já Gcebile pode desenvolver trabalhos de maior consistência, uma vez que seus participantes tendem a ser mais independentes podendo se comprometer com a continuidade dos processos criativos. Gcebile dirigiu o espetáculo Isaro: aquele que foi esquecido em processo colaborativo com os participantes em 2011, e que vem sendo apresentado desde então. Em 2016, o espetáculo foi premiado no Grahamstown Festival, um dos mais importantes festivais nacionais de artes da África do Sul.

Figura 2 - Cena do espetáculo Isaro: aquele que foi esquecido, sob a direção de Gcebile Dlamini, que estreou em 2011 e segue sendo apresentado em festivais. Foto sem autoria

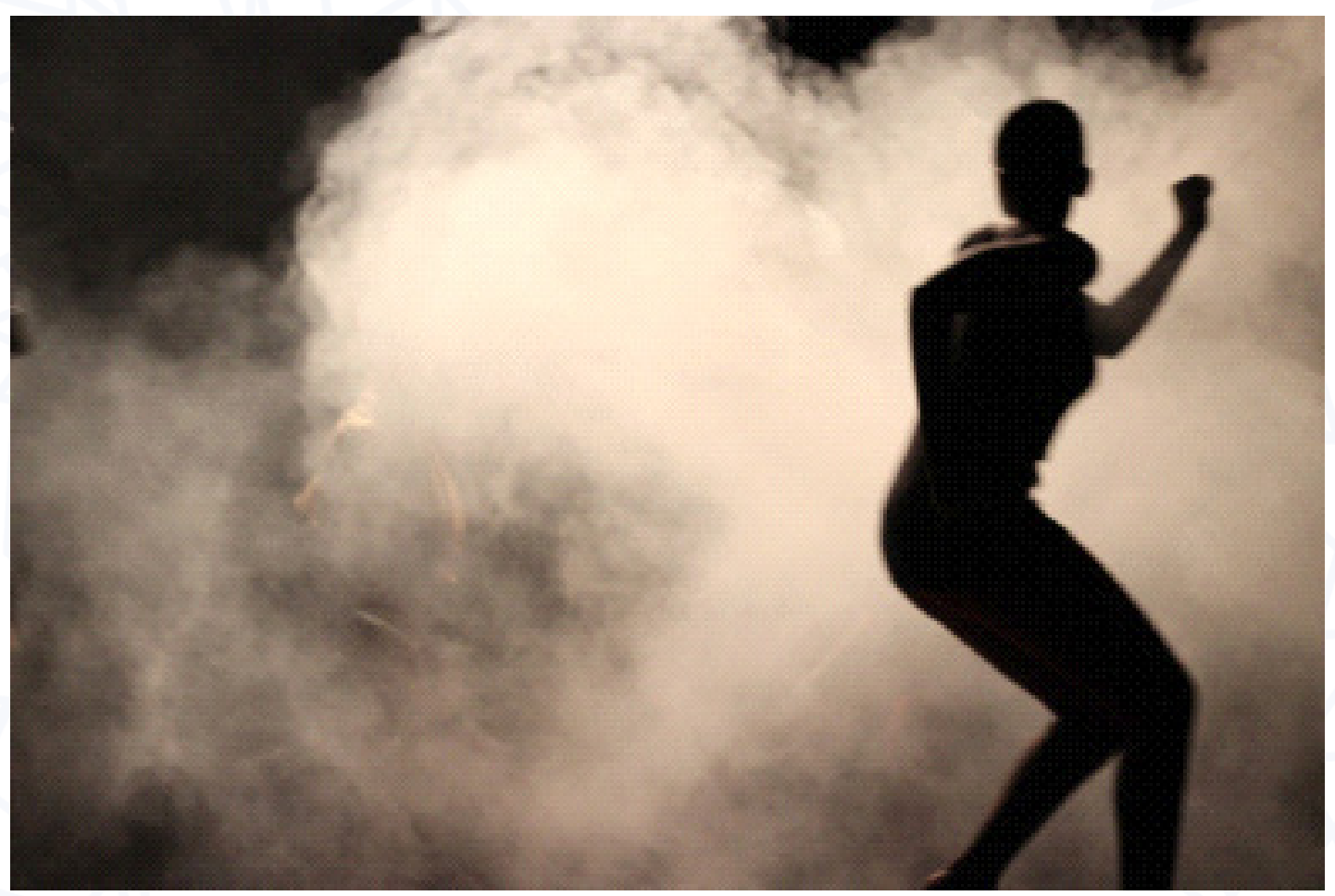

O High School Programme cumpre um papel importante de disseminação do teatro como prática de criação de sentido existencial, pois acontece fora do teatro, nas escolas primárias e secundárias da região central e em Soweto, e é coordenado por Mike e Phana. Eles são os facilitadores mais antigos do espaço, uma vez que já estavam atuando ali antes da constituição do Outreach em 2009. Por isso, eles fazem parte do grupo de idealizadores desse projeto, que começou com apenas algumas escolas ao redor do Teatro 
Hillbrow e hoje são, aproximadamente, quarenta escolas participando anualmente do projeto. Eles coordenam cerca de 31 facilitadores que atuam in loco nas escolas e, a partir desse projeto, acontece o High School Drama Festival. Em 2016, foi a décima segunda edição e participaram cerca de 450 jovens. Este projeto, portanto, trabalha o ano todo em produções teatrais nas escolas e, no final do ano, elas são apresentadas no Teatro Hillbrow numa grande celebração comunitária.

Gerard Bester é ator/facilitador/educador formado em artes dramáticas pela Wits University e fez especialização no Instituto Laban, em Londres, em Teoria do Movimento, durante quatro anos. Desde sua formação, despertou forte interesse pelos trabalhos comunitários, desenvolvendo projetos de teatro e dança em Soweto, antes de juntar-se ao Hillbrow. Nasceu e foi criado no bairro, é branco, ativista gay, casado e tem dois filhos negros adotados. Em sua adolescência, mesmo quando houve o período de transição, sua família permaneceu no bairro. Sua mãe, que engravidou muito jovem, em 1968, era ativista antiapartheid e, segundo ele, "ela só não era tida como feminista porque naquela época não tinha isso", disse em entrevista concedida para esta pesquisa.

Gerard Bester vem coordenando o Hillbrow desde 2009, a convite da Outreach. $\mathrm{Na}$ época, trabalhava fortemente em Soweto, e achou que seria uma excelente oportunidade retornar às suas origens para trabalhar pelo bairro onde nasceu. Porém, fala repetidamente sobre desistir do trabalho no espaço por conta das dinâmicas de transformação. Apesar de sua origem simples e de luta, de seu trabalho comprometido com a arte política e com o social, ele faz de sua vida um ato ético (CABALLERO, 2011) e sente a pressão de discursos sobre racismo institucional por ser um branco ocupando um cargo de liderança num teatro localizado num bairro majoritariamente negro.

Porém, os relatos coletados até agora não demonstram que, na estrutura interna do projeto, os facilitadores estejam descontentes com o fato de Gerard ocupar um cargo de liderança, ao contrário, sem que esta questão tenha sido trazida à tona, todos os facilitadores com quem conversei até agora demonstram profunda gratidão, respeito e admiração por ele. Todavia, no mapeamento dos relatos pude ter poucas, porém longas, conversas com os facilitadores do Teatro Hillbrow. A partir delas, as histórias se revelam, lentamente, sobre o 
agora e o antes - ainda que sobre o antes os relatos sejam temerosos ou tímidos. Há indícios de que a coleta de relatos acerca do período específico da transição, entre 1990 a 2009, quando então a Outreach Foundation se estabelece ali, revelará mais a frente na pesquisa, cosmologias importantes da configuração das práticas teatrais atuais. Relatos como o do facilitador Linda Mike, na época um menino imigrante em situação de rua e com uma longa trajetória de travessias, servem como pistas.

Nascido na Zâmbia, de mãe sul-africana e pai zimbabuense, fugiu com seus pais de sua cidade natal para o Zimbabwe quando a Guerra do Cobre eclodiu. Estabeleceram-se na região de Matabeleland do povo Ndebele, majoritariamente engajado na ascensão no partido popular ZAPU (Zimbabwean African Popular Union). Quando Robert Mugabe do ZANU (Zimbabwean African Nacional Union) sobe ao poder, em 1980, como líder mão de ferro que expulsa os brancos colonizadores do país. Porém ele promove, por meio de incitações contraditórias, o genocídio do povo Ndebele de Matabeleland, seus opositores do ZAPU. Mais uma vez, a família foge para salvar-se da guerra e aporta em Soweto, onde a mãe possuía família de origem Zulu. Contudo, na cultura Zulu há o lobola, dote pago pelo noivo para a família da noiva. O pai de Mike nunca havia pagado o dote, pois além de não estar em solo sul-africano quando se casaram, não fazia parte de sua cultura essa tradição. Quando a família chegou na África do Sul, sua condição econômica era desfavorável, e ele não tinha como pagar o lobola. Os filhos do matrimônio, então, não foram aceitos pela nova família, e tiveram que viver nas ruas do centro de Johanesburgo. Mike, naquela época com 11 anos, para sobreviver nas ruas, fazia apresentações ritualísticas com máscaras ancestrais "pois era a única coisa que eu sabia fazer", conta ele.

Foi assim que Mike conheceu Michelle Barrow, uma facilitadora em teatro do oprimido que atuava em Hillbrow naquele momento oferecendo oficinas. Michelle Barrow é negra, caribenha, de Bridgestown - Barbados, uma pequena ilha entre a Martinica, Trinidade e Tobago. Numa pesquisa virtual descobri que ela é professora da Universidade de West Indies, na Jamaica e que é contadora de estórias, além de seguir com as práticas do teatro do oprimido. Ela estava em Hillbrow, no período de transição do país, trabalhando com um grupo de meninos em situação de rua, usando teatro fórum, e 
assim montaram a peça $A$ esperança perdida ${ }^{13}$ apresentada no próprio teatro. Mike conta que nunca mais deixou de fazer teatro, nem deixou o espaço, e que hoje ele tenta fazer pelos outros meninos, o que um dia fizeram por ele: indicar caminhos de sentido de vida por meio da arte. Ele, juntamente com o facilitador Phana Dube, atuam ali há aproximadamente vinte anos e ambos testemunharam a transformação do bairro.

Phana Dube trouxe relatos igualmente ricos. Ele é nascido em Zimbabwe, em Matabeleland. Nos primeiros anos de tomada do poder por Mugabe - 0 herói que liberta a antiga colônia inglesa de Rhodesia em 1979 e torna-se ditador feroz a partir de 2000 - a educação do país era considerada umas das melhores do continente africano. No currículo constavam estudos de filosofia, política e artes. Phana conheceu o teatro já na escola fundamental e ali desenvolvia danças tradicionais Ndebele. Quando Mugabe iniciou o processo de extermínio de seus opositores, Phana foi enviado por seus pais à Johanesburgo para viver com a irmã mais velha. Ele dançava nas ruas da cidade por subsistência, quando foi convidado a se juntar ao Projeto Muka ${ }^{14}$, de danças tradicionais, voltado para meninos em situação de rua, em Hillbrow. Em 2008, viajou com o Muka para Hamburgo, na Alemanha, onde se apresentou com o grupo Wilde Fire ${ }^{15}$, e em seu retorno, foi convidado a trabalhar como facilitador no teatro. Augusto Boal (2012) e Paulo Freire (2013) foram referências citadas por todos os integrantes do projeto.

Sem apoio governamental ou privado, o espaço usa como dispositivo de sustentabilidade o aluguel de salas internas do teatro para cultos de igrejas pentecostais nas horas vagas, o que se torna um grande paradoxo de valores e de sacralidade. Enquanto o fazer teatral busca uma discussão política e um olhar crítico da realidade, os cultos religiosos pentecostais visam a uma docilização dos seus seguidores. Mesmo com essa contradição, o aluguel das salas para cultos é crucial, pois viabiliza o projeto teatral. A ONG luta para sua permanência e subsistência também por meio de doações. Apesar das dificuldades, os projetos estabelecem uma relação continuada com a comunidade,

13. No original: The lost hope.

14.Disponível em: <https://goo.gl/QgrLgG>. Acesso em: 23 jul. 2017.

15. Disponível em: <https://goo.gl/Gz4vyH>. Acesso em: 23 jul. 2017. 
podendo investir na construção de integração e resiliência, usando a realidade do entorno como temática principal em suas discussões.

Por fim, as premissas que sustentam o pensamento crítico desse fazer teatral, que se situa nas bordas do político e do social, são muito imersas nas questões humanas da memória daqueles que transitam no espaço. A dinâmica de criação de sentido existencial a partir de práticas teatrais que bebem da fonte da vida no bairro resulta na formação de jovens cidadãos que pensam criticamente suas experiências ali. É esse tipo de teatro - relacional, que se mistura e que se envolve com questões sociais e que vão além da estética que instiga seus criadores e facilitadores.

\section{Referências bibliográficas}

BAUMAN, Z. Comunidade: a busca por segurança no mundo atual. Tradução Plínio Dentzien. Rio de Janeiro: Jorge Zahar, 2003.

BOAL, Augusto. Teatro do Oprimido. São Paulo: Civilização Brasileira, 2012.

BREMMER, L. Reinventing the Johannesburg inner city. Cities: The International Journal of Urban Policy and Planning, Amsterdam, v. 17, n. 3. p. 185-193. 2000.

CABALLERO, I. D. Cenários liminares: teatralidades, performances e política. Tradução Luis Alberto Alonso e Angela Reis. Uberlândia: UFU. 2011. p. 208. (Coleção teoria Teatral Latino Americana).

FREIRE, P. A pedagogia do oprimido. 54. ed. Rio de Janeiro: Paz e Terra, 2013. 253 p. LANDAU, L. B. Mobility and metanarrative: revisiting South African social science through migration and displacement. In: INAUGURAL LECTURE UNIVERSITY OF THE WITWATERSRAND, 18 jun. 2014, Johannesburg.

NEGRI, A.; HARDT, M. Declaração, isto não é um manifesto. Tradução Carlos Szlak. 2. ed. São Paulo: N1 Edições, 2016.

NOLETO, R. S.; ALVES, Y. C. Liminaridade e communitas: Victor Turner. In: A Enciclopédia. São Paulo: Faculdade de Filosofia, Letras e Ciências Humanas FFLCH, Universidade de São Paulo. 8 dez. 2015. Disponível em: <https://goo.gl/ nt1QBX>. Acesso em: 24 jul. 2017.

PELBART, P. P. Elementos para uma cartografia da grupalidade. In: SAADI F.; GARCIA

S. (org.). Próximo ato: questões da teatralidade contemporânea. São Paulo: Itaú Cultural. 2008. p. 33-37.

POVINELLI, E. Economies of abandonment: social belonging and endurance in late liberalism. Durham: Duke University Press, 2011.

POVINELLI, E. Geontologia do aquilo-outro. Tradução: Adriana Miranda da Cunha e

Paloma Bianchi. Urdimento, Florianópolis, v. 2. n. 27, p. 418-422, 2016. 
TURNER, V. The ritual process: structure and anti-structure. Piscataway: Transaction

Publishers. 1995. $213 p$.

WILHELM-SOLOMON, M. Prophets of the city. In: PAMPALONE, T.; ACCONE, D. Writing invisibility: conversations on the hidden city. Johannesburg: Mail and Guardian; Milwaukee: ACMS, 2013. p. 34-46.

Recebido em 24/04/2017

Aprovado em 10/06/2017

Publicado em 05/09/2017 